\title{
Design of Enterprise Vehicle Use Management System
}

\author{
Tao Peng ${ }^{1, a}$, Ai-sheng Ren ${ }^{2, b^{*}}$, Jia-ji Zhang ${ }^{1, c}$ and Shu-hong Guo ${ }^{1, d}$ \\ ${ }^{1}$ School of Science, East China University of Technology,Nanchang, China \\ ${ }^{2}$ Institute of Agricultural Economics and Development,Chinese Academy of Agricultural Sciences, \\ Beijing, China \\ apengtao@ecit.cn, baishengren@caas.net.cn, cjjzhang@ecit.cn, dshguo@ecit.cn
}

Keywords: enterprise; vehicle; management system

\begin{abstract}
The design of enterprise vehicle use management system uses JAVA development design language, Microsoft SQL Server as the main development tools. The structured development methods is used to design a $\mathrm{C} / \mathrm{S}$ structure of information management system. Through the analysis, the system finally is divided into basic information management, vehicle information management, personnel management, driver management, application management and vehicle use management. After the completion of the design and development, the system could be good use of vehicles to carry on the reasonable and effective management.
\end{abstract}

\section{Introduction}

With the continuous increase of vehicle in enterprises, vehicle management had become an important daily management of the company. Enterprises are facing many problems about use of the vehicle, such as the application for the use of the staff was not convenient, supervision for the use of vehicles was difficult, vehicle use time is not standardized, vehicle use charge is not uniform, etc.. In order to let the management to know the situation of each car in time, to coordinate and arrange the needs of the employees, and to improve the use efficiency of the vehicle, a vehicle use management system which has the characteristics of networking, informatization and standardization need to be established.Safety management interventions have been effective in reducing injury outcomes in occupational health and safety (OHS) and road safety, and assesses their applicability to reducing crash and injury outcomes in heavy vehicle transport ${ }^{[1]}$.Power management system that includes the managements of the information of identifying the custom, energy metering, selfmanagement of pricing and settling accounts and warning to custom is core design of mobile power station for electric vehicles ${ }^{[2]}$.To meet the need of vehicle management and control in the vehicle transportation enterprise, Wang Ya-jun ${ }^{[3]}$ puts forward the strategy and configuration model of system integration based on the middle layer, discusses general function of the integrated system, conversion and update of the integrated information, and the solution to working process of integration control. The article used JAVA language and Microsoft SQL Server as the main development tool, used the structured development method, developed the vehicle information management system based on $\mathrm{C} / \mathrm{S}$ structure to promote effective management of the vehicle basic information, vehicles using application, vehicle out and return management and driver management.

\section{Key Development Technology}

Eclipse. Eclipse is a well-known and free integrated development environment (IDE), which is 
just served as a framework and a set of services, and build the development environment through the plug-in components. Various development needs of users can be meet through the installation of these plug-ins, Such as the programming language development of UML, C++, COBOL, Eiffel , etc..

JAVA and Java Development Kit (JDK) . JDK is a program development environment for writing applet Java and application. It consists of an operating environment that is in the operating system layer, the Java application of the applet and the application program.

Microsoft SQL Server 2008. Server SQL 2008 can directly store the structured, semi-structured and unstructured documents in the database ${ }^{[4]}$, and can query, search, synchronize, report and analyze the data. It is able to provide the database services required by the ultra large systems $^{[5]}$.

\section{System Design}

System Function Analysis. The enterprise vehicle management system must firstly realize the management function of the basic data. Secondly, the functions of vehicle management, personnel management, driver management, application management and vehicle return management must be provided.

System Structure Design. Based on the system function analysis, the enterprise vehicle management system is divided into several modules, such as vehicle management, driver management, vehicle application, application processing, vehicle registration and so on. These elements are shown in the functional block diagram, which is more clear about the relationship between the structure of the system and the module. The structure of enterprise vehicle management system is shown in figure 1 .

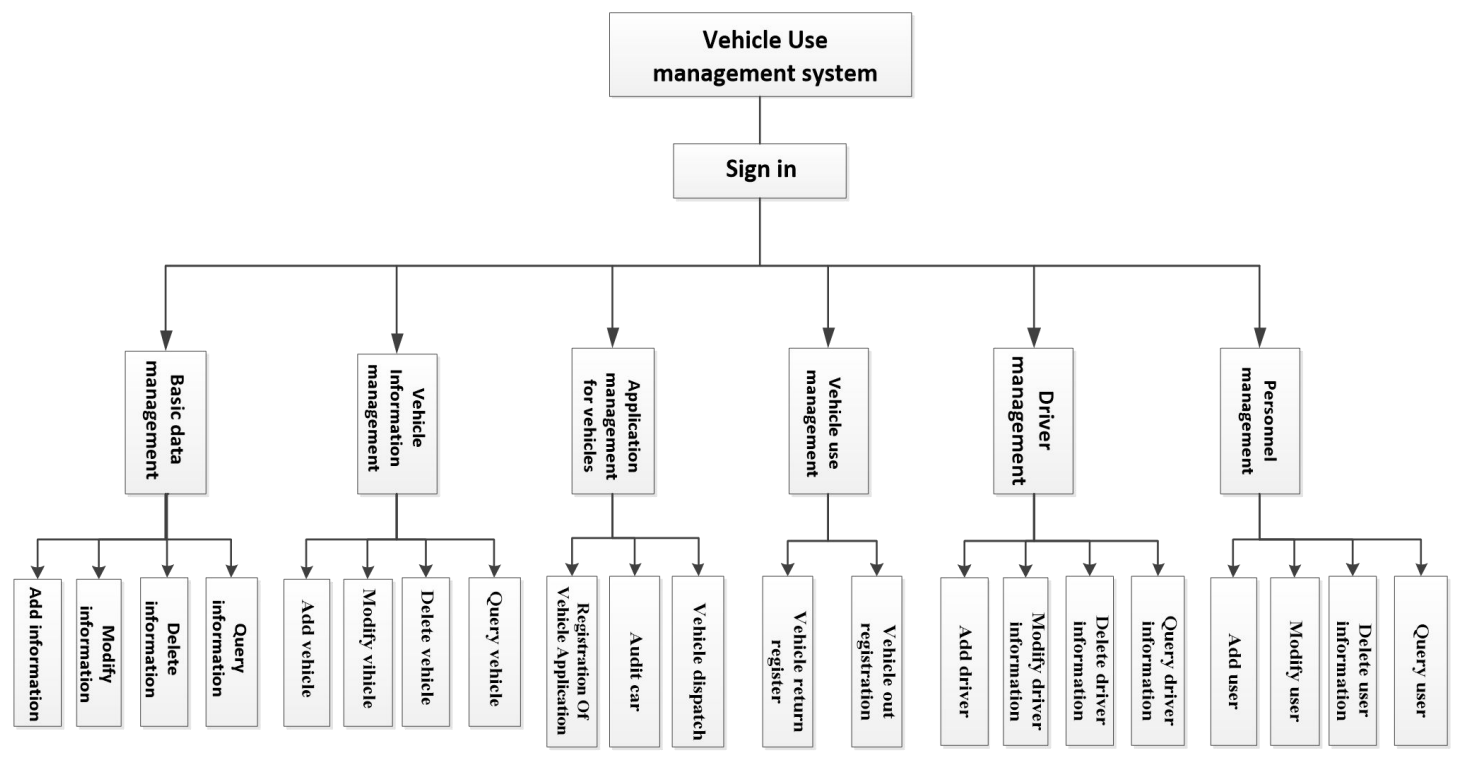

Figure.1 The structure of enterprise vehicle management system

\section{System Function Module Design}

Basic data management module. The module manages the basic data of the system, such as: Department, position, cost standards, vehicle model, audit type and other basic data, the process of management is shown in figure 2 .

Vehicle Information Management Module. The module mainly manages the information of vehicle, which can increase, delete, change, check the the information of vehicle, the process is 
shown in figure 3.

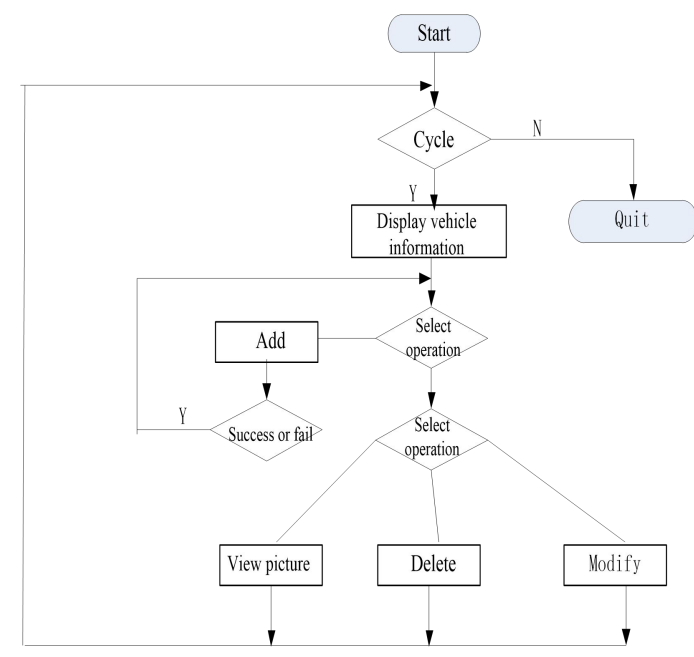

Figure.2 The process of basic data management

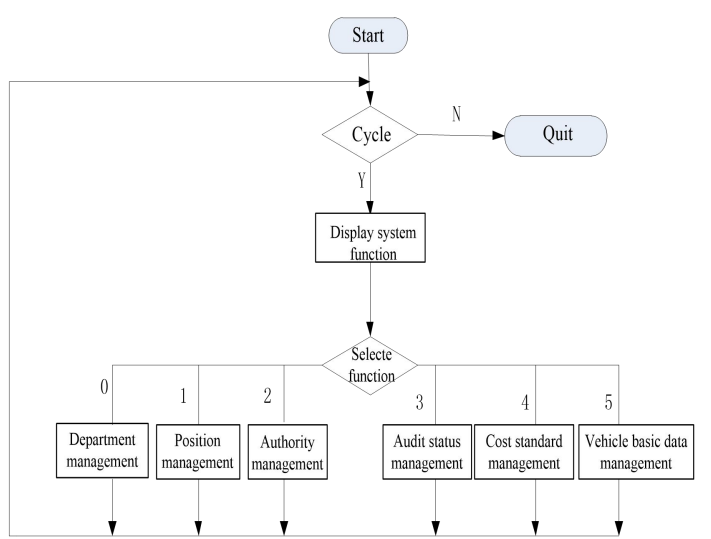

Figure. 3 The process of information management of vehicle

Vehicle Application Management Module.The module includes two sub modules, which are the use application of the vehicle and the application process. Users fill out, submit, modify the use application of vehicle; managers review the application, modify the audit, send a car, modify mission and other operations, the process is shown in figure 4.

Vehicle Use Management Module. The module includes two sub modules, which are registration of vehicle use and registration of vehicle return. Garage management personnel register, modify, delete the vehicle use information according to the document of vehicle dispatch. At the same time, the garage administrator register and calculate cost according to the vehicle which is returned, the process is shown in figure 5.

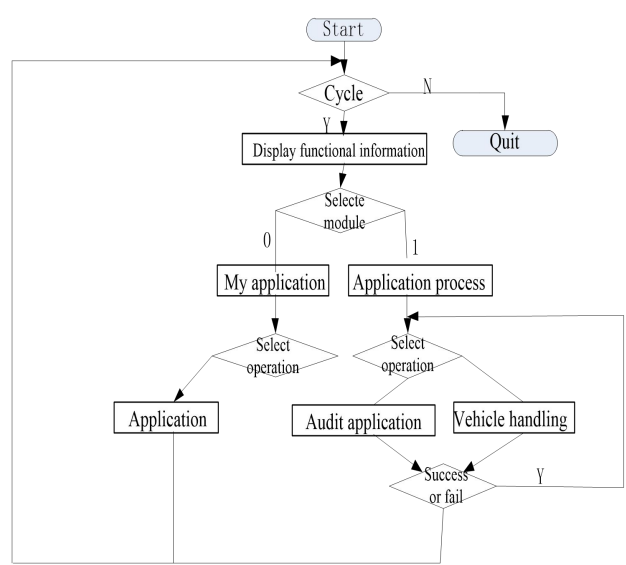

Figure. 4 The process of vehicle Application management

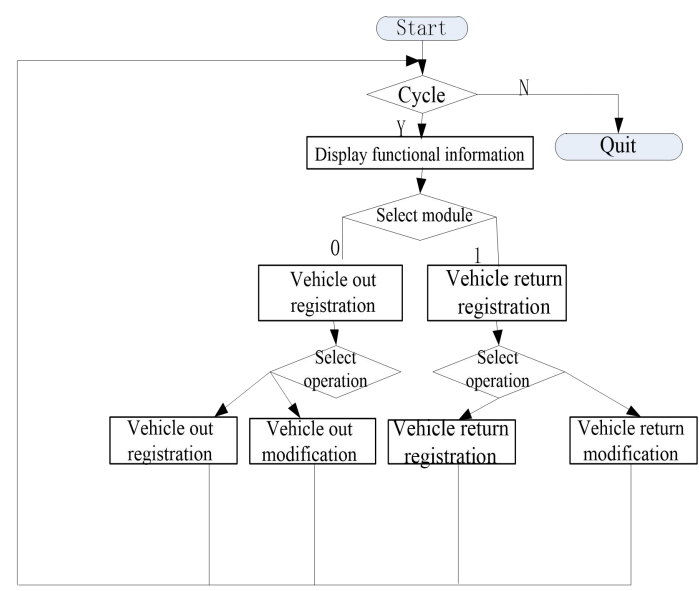

Figure. 5 The process of vehicle use management

Driver Management Module. The module mainly manages the information of driver, which can increase, delete, change, check the the information of driver, the process is shown in figure 6.

\section{Database Design}

E-R method is used for the concept design of database. First,the local E-R model of each module is designed, and then the E-R mode of each module are integrated into a global mode, and finally the global E-R model was optimized to get the final model. The main relationship model of the system database is shown in figure 7. 


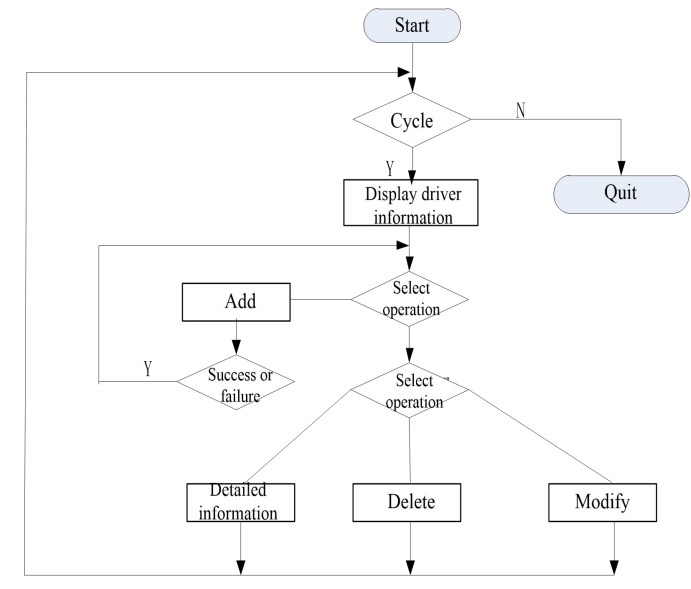

Figure.6 The process of information management of driver

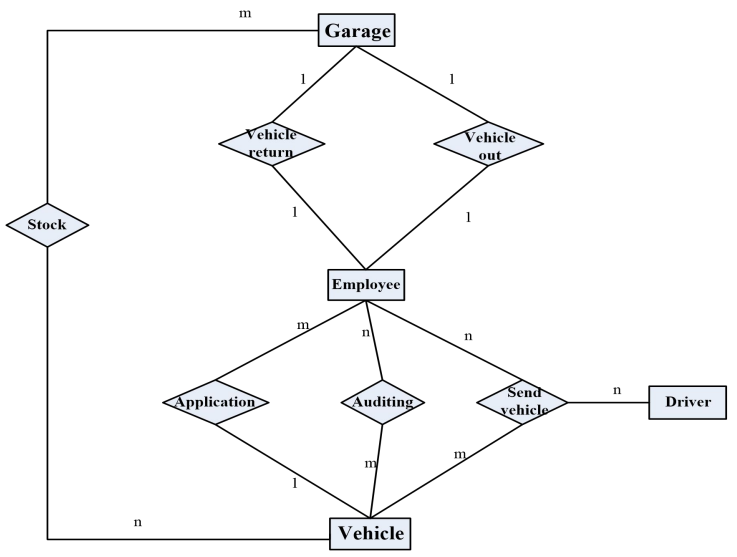

Figure.7 E-R diagram of system entity contact

\section{Summary}

The focus of the system design is the vehicle use, which is mainly for vehicle application, review, scheduling, dispatch and return, in order to realize the electronic and standardized management of the whole process. The system is divided into basic information management, vehicle information management, personnel management, driver management, application management and vehicle use management. Each module has the necessary data connection, which make up an integral whole. The system mainly uses the $\mathrm{C} / \mathrm{S}$ mode structure which is developed by Swing Java and Microsoft SQL Server database.

\section{Acknowledgment}

The research reported in the article was funded by East China University of Technology Dr. Fund project(DHBK1004).

\section{Contact of Corresponding Author}

Ai-sheng Ren, aishengren@caas.net.cn, 010-82109798

\section{References}

[1] Lori Mooren,Raphael Grzebieta,Ann Williamson, et al.Safety management for heavy vehicle transport: A review of the literature[J].Safety science,2014,62:79-89.

[2]Yu Zhang Minghong Zhang and Jianning Yang.Design of Energy Management Systems for Mobile Power Station of Electric Vehicles[J].2009 International Conference on Information Management, Innovation Management and Industrial Engineering.2009:250-253.

[3]Wang Ya-jun,Liu Wei,He Song-bai, et al.Study on the Vehicle Management and Control Information System Integration of Vehicle Transportation Enterprise[C]. The 4th International Conference on Wireless Communications, Networking and Mobile Computing.2008:1-5.

[4]Zhao Hong-qiang, Zhang Jin-yuan, Li Jun. Design and realization of unified management system on vehicle located on different places based on RFID[J].Information Technology,2015,(1): 159-162. [5]Li Yu, Dong Xiang-ying. Design and Application of Vehicle Equipment Inventory Management Database[J]. Logistics Technology, 2010,29(6):306-308,311. 